\title{
A Ten Years Retrospective Study of Hysterectomy in Goba Referral Hospital, Bale Zone, South East Ethiopia, Magnitude Indications and Outcomes
}

Aklilu Getachew ( $\square$ akeachew.2@gmail.com )

Jimma University

Takele Mengistu

Jimma University

Yaregal Asres

Bahir Dar University

Original Article

Keywords: Maternal health, Hysterectomy, obstetric problem, uterine ruptures, indication, outcomes, Goba Referral Hospital.

Posted Date: September 17th, 2020

DOI: https://doi.org/10.21203/rs.3.rs-77029/v1

License: (c) (i) This work is licensed under a Creative Commons Attribution 4.0 International License. Read Full License 


\section{A Ten Years Retrospective Study of Hysterectomy in Goba Referral Hospital,}

Bale Zone, South East Ethiopia, Magnitude Indications and Outcomes

Aklilu Getachew ${ }^{1 *}$ Takele Mengistu ${ }^{2}$, Yaregal Asres ${ }^{3}$

${ }^{1}$ School of Medical Laboratory Science, Faculty of Health Sciences, Institute of Health, Jimma University, Jimma, Ethiopia

${ }^{2}$ School of Medical Science, Faculty of Medical Science, Institute of Health,Jimma University, Jimma, Ethiopia

${ }^{3}$ Department of Medical Laboratory Science, School of Health Sciences, College of Medicine and Health Science, Bahir Dar University, Ethiopia

Authors' email address

Akililu Getachew:akeachew.2@gmail.com/aklilu.mamo@ju.edu.et

TakeleMengistu :takemenge80@gmail.com

YaregalAsres :yaregala3@gmail.com

*Corresponding author: Aklilu Getachew: -School of Medical Laboratory Sciences, Faculty of Health Sciences, Institute of Health, Jimma University, Ethiopia

Email:akeachew.2@gmail.com/aklilu.mamo@ju.edu.et

Skype: akeachew.2

Tel: +251911743331 


\section{ABSTRACT}

Background: Hysterectomy is one of the major surgeries performed in clinical practice for commonly encountered diseases of the female genital tract worldwide. Even if Hysterectomy is widely performed surgery in both developed and low income countries little is known about is epidemiology in rural part of develop countries. Especially in developing countries like Ethiopia representative reliable statistics are rarely available on this important aspect of women's health mainly on its prevalence, indication and outcome. So the aim of this study was to assess the magnitude indication and outcome of hysterectomy in Goba Referral Hospital from January 1, 2008 to January1, 2018.

Methods: institutional based retrospective study was conducted in Goba Referral Hospital. Self-administered structured checklists were used to collect the data. The data were entered into Epi data version 3.1 and analyzed by SPSS version 20. Continuous and categorical variables were summarized by tables, graph and descriptive statistics. Logistic regression was used to determine association between predictors and Hysterectomy prevalence. P-value $<0.05$ was -considered as statistically significant.

Results: a total of 200 hysterectomies were done for obstetrics and gynecology indications, of which the commonest, $47 \%(n=94)$, indication was uterine rupture. From the total of 116 women, who had no antenatal care follow up, $40 \%(n=47)$ had uterine rupture. This study also indicated that, most of uterine rupture cases $80 \%(n=76)$ were living far away from the hospital (> 50km from the hospital) $94.6 \%$ (n-89) were multiparous. This study has also indicated that from the total of 20 discharged dead, $90 \%(n=18))$ were came from a distance of $>100 \mathrm{~km}$ far from the hospital and 95\% (n=19) were those who didn't attend antenatal care.

Conclusions: the higher rate of uterine rupture was seen in those who were multi Para, far from Hospitals and those who have no ANC follow up. Large scale study for the identification of determinant factors for evidence based intervention will be very important.

\section{Key words:}

Maternal health, Hysterectomy, obstetric problem, uterine ruptures, indication, outcomes, Goba Referral Hospital. 


\section{Introduction}

\subsection{Background}

Hysterectomy is defined as the removal of the uterine corpus with or without the cervix. The two mainly performed hysterectomies worldwide includes total hysterectomy which remove the uterine corpus with the cervix and the one which removes without the cervix is subtotal or supra cervical hysterectomy. Depending up on the clinical case and the condition in facilities the hysterectomy procedure can be performed via laparotomy, vaginally, by applying minimally invasive techniques (laparoscopy, robotic surgery) or a combination of the latter two [1][2].

Hysterectomy was invented to manage life-threatening obstetric hemorrhage and uterine sepsis and was first performed successfully by Porro in 1871.1 By the 1950s, it had become an elective procedure (including for sterilization) and became controversial as a result of the risk of blood loss and urinary tract injury. But today, emergency peripartum hysterectomy is performed as a life-saving operation only. The term includes hysterectomies after cesarean delivery as well as vaginal delivery[3].

Hysterectomy is the second most commonly performed major surgical procedure in females worldwide next to caesarean section. This procedure is the leading reason for non-Obstetric surgery among women in highly income setting. Every year, many women all over the word undergo hysterectomy, the removal of their uterus. According to the reports in literature, approximately 600,000 hysterectomies are performed annually in the United States, 100,000 in the UK, and 36,000 in Australia.[4]

Hysterectomy is a successful operation in terms of symptoms relief and patient satisfaction, the usual indications for the operation includes conditions like bleeding problems, uterine leiomyoma, endometriosis and uterine prolapse, and malignant conditions of the internal genital tract. Most common indications were placental pathology, uterine atony and uterine rupture. [5][3]

Even though this procedure is primarily done to save women from uterus-related lifethreatening problems and for a better and healthy life, reports shows it has also negative impact on the patient psychological and physical well being . Hysterectomy related psychological morbidity typically includes depression, anxiety, and stress-related symptoms, it could be triggered by negative perceptions about body image, femininity, youth, energy and 
activity levels, as well as loss of child-bearing capacity which resulted from the complications that follows the procedure like vaginal cuff dehiscence and injuries to nervous, urinary, and gastrointestinal structures [6][7]

Globally maternal death is increasing alarmingly. The main Couse of death includes pregnancy and childbirth-related complications which directly or indirectly related with the number and the needs of hysterectomy worldwide. Traditionally, the causes of maternal mortality have been classified as direct and indirect, each contributing to about $70 \%-80 \%$ and $20 \%-30 \%$ of the total maternal deaths, respectively. It is also known that the major causes of maternal deaths are similar across low income countries like Ethiopia, often obstetric in origin, and generally follow obstructed labor with or without rupture, hypertensive disorders (mainly severe preeclampsia and eclampsia), infection and hemorrhage (mainly placenta previa/abruption, urine rapture and postpartum hemorrhage) [8][9]

At present, women undergoing hysterectomy stay for a shorter period of time in hospital and experience the healing process in their homes. In several studies, it has been showed that women want information and advices on type of surgery, difficulties that may be encountered after surgery, the possible complications of the hysterectomy, problems in course of healing process and care. Therefore, providing training about needs before and after hysterectomy and evaluating femininity perceptions of women undergoing hysterectomy is of great importance for comprehensive nursing care[10]

In many parts of the world, medical care particularly obstetric care has reached such a high level that maternal mortality has nearly disappeared and infant losses are declining steady. The application of existing knowledge to all groups of the population would produce even further improvement [11][12] However, in the under developed parts of the world where Ethiopia is one of them, maternal mortality has been little improved by modern maternity care which so far large proportion of the mother's wider dissemination has been hampered by shortage of trained midwives, doctors, obstetricians and money to support them and provide hospital and maternity centers [13].

Even though there is limited data about hysterectomy in Ethiopia, few studies indicated that, there is a high incidence of complication of pregnancy and labor. The number of cases of uterine rupture is high not only because of poor or in adequate antenatal care but also because of poor transportation and communication system. It is not unusual for patients with ruptured uterus to travel along distance and arrive in hospital in a moribund condition only 
to die within a few hours. Lack of awareness and education about antenatal care; and poor economic conditions, previous mode of delivery play an important role and a large numbers of maternal deaths occur because of these conditions. Women operated for emergency hysterectomy had high death outcome rate compared to elective hysterectomy respectively. [8][13][14].Therefore our study was aimed to assess the magnitude, indications and outcomes of hysterectomy in Goba Referral Hospital, Bale Zone, South East Ethiopia.

\section{Results}

Among 200 women 116(58\%) had ANC follow up the others did not attend ANC follow up during their previous pregnancies. (Table 1)

Table 1: Distribution of socio demographic characteristics of patients with maternal health related cases at Goba Referral Hospital, Bale Zone, Oromia region south east Ethiopia from January1, 2008 to January 1,2018 .

\begin{tabular}{|l|l|l|l|}
\hline \multicolumn{2}{|l|}{ Variables } & Numbers & Percent's \\
\hline Address & Rural & 190 & 95 \\
\cline { 2 - 4 } & Urban & 10 & 5 \\
\cline { 2 - 4 } & Total & 200 & 100 \\
\hline Age & $15-19$ & 4 & 2 \\
\cline { 2 - 4 } & $20-29$ & 92 & 46 \\
\cline { 2 - 4 } & $30-39$ & 88 & 44 \\
\cline { 2 - 4 } & $40+$ & 16 & 100 \\
\cline { 2 - 4 } & Total & 200 & 42 \\
\hline \multirow{5}{*}{ ANC } & Yes & 84 & 58 \\
\cline { 2 - 4 } & No & 116 & 100 \\
\cline { 2 - 4 } & Total & 200 & \\
\hline
\end{tabular}


The most Common indications for hysterectomy was uterine rupture which accounts 94(47\%) and the least indication for hysterectomy was pelvic peritonitis post abortion procidentia which accounts $3(1.5 \%)$. (Table 2)

Table 2: Indications for hysterectomy in Goba Referral Hospital, Bale Zone, Oromia Region South East Ethiopia from January 1, 2008 to January1, 2018

\begin{tabular}{lll}
\hline Indications for hysterectomy & Number & \% \\
\hline Uterine rupture & 94 & 47 \\
Myoma & 72 & 36 \\
Pelvic peritonitis secondary to puerperal sepsis & 7 & 3.5 \\
Pelvic peritonitis post abortion procidentia & 3 & 1.5 \\
Procidentia & 24 & 12 \\
Total & 200 & 100 \\
\hline
\end{tabular}

Among 84 mothers who were attend ANC 83 (98.8\%) were discharged alive while others 1(1.2\%) discharged dead. On the other hand, 116 mothers had no ANC follow up from this 97(83.6\%) discharged alive but $19(16.3 \%)$ of them were dead. (Table 3)

Table 3: Distribution of cases of hysterectomy by maternal health status and antenatal care in Goba Referral Hospital, Bale Zone, OromiaRegion,South East Ethiopia from January 1, 2008 to Jaqnuary1, 2018.

\begin{tabular}{lllllll}
\hline $\begin{array}{l}\text { Antenatal } \\
\text { care }\end{array}$ & Alive & & dead & & Total & \\
& & & & & & \\
& & & & & & \\
& No & $\%$ & No & 1.2 & 84 & 100 \\
\hline Yes & 83 & 98.8 & 1 & 16.3 & 116 & 100 \\
\hline No & 97 & 83.6 & 19 & & & 100 \\
\hline Total & 180 & 90 & 20 & 10 & 200 & \\
\hline
\end{tabular}


Among 84 mothers who were attend ANC 47(56\%) were with uterine rupture and 37(44\%) were with no uterine rupture. On the other hand among 116 mothers had no ANC follow up 47(40\%) were with uterine rupture and 69(60\%) were with no uterine rupture. (Table 4)

Table 4: Distribution of cases of uterine rupture \& antenatal care follow up in Goba Referral Hospital, Bale Zone, Oromia Region South East Ethiopia from January 1, 2008 to Jaqnuary1, 2018

\begin{tabular}{lllllll}
\hline Variable & \multicolumn{3}{c}{ Uterine rupture } & \multicolumn{2}{c}{ Total } \\
\cline { 2 - 6 } & & Yes & $\%$ & No & $\%$ & \\
\hline History of ANC & yes & 47 & 56 & 37 & 44 & 84 \\
\cline { 2 - 6 } follow up & No & 47 & 40 & 69 & 60 & 116 \\
\hline Total & & 94 & 47 & 106 & 53 & 200 \\
\hline
\end{tabular}

From the total study subjects 94 were with uterine rupture from those majorities of them 76(80\%) travels more than 50km distance to arrive Goba Referral Hospital. (Table 5)

Table 6: Distribution of cases of Uterine Rupture "Vs"' Distance from Goba Referral Hospital, Bale Zone, Oromia region from January 1, 2008 to Jaqnuary1, 2018.

\begin{tabular}{|c|c|c|c|c|c|c|c|c|c|c|}
\hline \multirow[t]{3}{*}{ Variable } & & \multicolumn{6}{|c|}{ Distance in $\mathbf{k m}$} & & & \multirow[t]{3}{*}{ Total } \\
\hline & & \multicolumn{2}{|c|}{$<20 \mathrm{~km}$} & \multicolumn{2}{|c|}{$20-50 \mathrm{~km}$} & \multicolumn{2}{|c|}{$50-100 \mathrm{~km}$} & \multicolumn{2}{|c|}{$>100 \mathrm{~km}$} & \\
\hline & & No & $\%$ & No & $\%$ & No & $\%$ & No & $\%$ & \\
\hline \multirow{2}{*}{$\begin{array}{l}\text { Uterine } \\
\text { rupture }\end{array}$} & yes & 18 & 19 & $\mathbf{0}$ & $\mathbf{0}$ & 38 & 40 & 38 & 40 & 94 \\
\hline & No & 8 & 7.5 & 2 & 1.8 & 55 & 52 & 41 & 38.6 & 106 \\
\hline Total & & 26 & 13 & 2 & $\mathbf{1}$ & 93 & 46.5 & 79 & 39.5 & 200 \\
\hline
\end{tabular}


In this study majority of uterine rapture was happened in the parity level 2 which was diagnosed case for 27 (28.7\%) mothers out of the total 94 mothers with uterine rupture, the list was happened in parity level 0 which accounts $5(5.3 \%)$. (Table 6)

Table 6: Distribution of cases of Uterine Rupture "Vs" Parity in Goba Referral Hospital, Bale Zone, OromiaRegionSouth East Ethiopia from January 1, 2008 to Jaqnuary1, 2018

\begin{tabular}{lcccccc}
\hline & & \multicolumn{3}{c}{ Uterine rupture } & Total \\
\cline { 3 - 7 } Parity & Yes & $\%$ & No & $\%$ & \\
\cline { 2 - 7 } & 0 & 5 & 35.7 & 9 & 64.3 & 14 \\
& 1 & 21 & 37.5 & 35 & 62.5 & 56 \\
& 2 & 27 & 58.7 & 19 & 41.3 & 46 \\
& 3 & 10 & 43.5 & 13 & 56.5 & 23 \\
& 4 & 25 & 50 & 25 & 50 & 50 \\
\hline Total & 5 & 6 & 54.5 & 5 & 45.5 & 11 \\
\hline
\end{tabular}


Among 200 women for whom hysterectomy was done 92 of them were in the age 20-29 among this $46.7 \%$ were para II-IV and 88 of them were in the Age group of 30-39, out of this 71.6\% were para II-IV. (Table 7)

Table 7: Distribution of maternal death due to hysterectomy by age and parity in Goba Referral Hospital, Bale Zone, Oromiaregionsouth east Ethiopia from January 1, 2008 to Jaqnuary1, 2018.

\begin{tabular}{|c|c|c|c|c|c|c|c|c|c|c|}
\hline \multirow[t]{3}{*}{ Age group } & \multicolumn{10}{|c|}{ PARITY } \\
\hline & \multicolumn{2}{|l|}{ 0 } & \multicolumn{2}{|l|}{ I } & \multicolumn{2}{|c|}{ II-IV } & \multicolumn{2}{|c|}{$>I V$} & \multicolumn{2}{|c|}{ Total } \\
\hline & № & $\%$ & № & $\%$ & № & $\%$ & № & $\%$ & $\mathbf{N}^{\mathbf{0}}$ & $\%$ \\
\hline $15-19$ & 0 & 0 & 0 & 0 & 3 & $75 \%$ & 1 & $25 \%$ & 4 & 100 \\
\hline $20-29$ & 8 & $8.7 \%$ & 38 & $\begin{array}{l}41.3 \\
\%\end{array}$ & 43 & $\begin{array}{l}46.7 \\
\%\end{array}$ & 3 & $3.2 \%$ & 92 & \\
\hline 30-39 & 4 & $4.5 \%$ & 16 & $\begin{array}{l}18.2 \\
\%\end{array}$ & 63 & $\begin{array}{l}71.6 \\
\%\end{array}$ & 5 & $5.7 \%$ & 88 & 100 \\
\hline $40+$ & 2 & $\begin{array}{l}12.5 \\
\%\end{array}$ & 2 & 12.55 & 10 & $\begin{array}{l}62.5 \\
\%\end{array}$ & 2 & 12.55 & 16 & 100 \\
\hline Total & 14 & $7 \%$ & 56 & $28 \%$ & 119 & $\begin{array}{l}59.5 \\
\%\end{array}$ & 11 & $5.5 \%$ & 200 & 100 \\
\hline
\end{tabular}


Out of 20 mothers who discharged dead $18(90 \%)$ were came from a distance $>100 \mathrm{~km}$ and no patients discharged dead from those who came from $<20 \mathrm{~km}$. (Table 8)

Table 8: Distribution of cases of hysterectomy, maternal health status and distance of locality fro to Jaqnuary1, 2018m Goba Referral Hospital, Bale Zone, Oromia region south east Ethiopia from January 1, 2008

\begin{tabular}{|c|c|c|c|c|c|c|c|c|c|c|}
\hline & \multicolumn{8}{|c|}{ Distance in km from Goba Referral Hospital } & \multicolumn{2}{|c|}{ Total } \\
\hline & \multicolumn{2}{|c|}{$<20 \mathrm{~km}$} & \multicolumn{2}{|c|}{$20-50 \mathrm{~km}$} & \multicolumn{2}{|c|}{$50-100 \mathrm{~km}$} & \multicolumn{2}{|c|}{$+100 \mathrm{~km}$} & & \\
\hline & $\mathbf{N}^{\underline{\mathbf{o}}}$ & $\%$ & $\mathbf{N}^{\underline{\mathbf{o}}}$ & $\%$ & № & $\%$ & № & $\%$ & No & $\%$ \\
\hline Alive & 26 & 14.4 & 1 & 0.6 & 92 & 51 & 61 & 34 & 180 & 90 \\
\hline Dead & 0 & & 1 & 5 & 1 & 5 & 18 & 90 & 20 & 10 \\
\hline Total & 26 & 13 & 2 & 1 & 93 & 46.5 & 79 & 39.5 & 200 & 10 \\
\hline
\end{tabular}


Distance and ANC follow up are statistically related with uterine rupture at p-value 0.039 $(\mathrm{p}<0.05)$ and $\mathrm{p}$-value $0.001(\mathrm{p}<0.05)$ done by chi-square respectively. Mothers came far away from the hospital and those who didn't attend ANC are more suffered from uterine rupture.

(Table 9)

Table 9: Associated factors with uterine rupture in Goba Referral Hospital, Bale Zone, Oromia region south east Ethiopia from January 1, 2008 to Jaqnuary1, 2018

\begin{tabular}{|l|l|l|}
\hline Variable & Category & P-value \\
\hline ANC & yes & \\
\hline & No & 0.001 \\
\hline Distance & $<20$ & \\
\hline & $20-50 \mathrm{~km}$ & \\
\hline & $50-100 \mathrm{~km}$ & \\
\hline & $>100 \mathrm{~km}$ & 0.039 \\
\hline
\end{tabular}

ANC is statistically associated with discharge condition to be died at $p$-value $0.001(p<0.05)$ done by chi -square test. Mothers those didn't attend ANC were more likely discharged dead.

(Table 10)

Table 10: Associated factors with Discharge out come in Goba Referral Hospital, Bale Zone, Oromia regionsouth east Ethiopia from January 1, 2008 to Jaqnuary1, 2018

\begin{tabular}{|l|l|l|}
\hline Variable & category & p-value \\
\hline ANC & Yes & \\
\cline { 2 - 3 } & No & 0.001 \\
\hline
\end{tabular}




\section{Discussion}

In many parts of the world, medical care particularly obstetric care has reached such a high level that maternal mortality has nearly disappeared and infant losses are declining steady. In Ethiopia, there's a high incidence of complication of pregnancy and labor. The number of cases of uterine rupture is high not only because of poor or in adequate antenatal care but also because of poor transportation and communication system. Our study was also targeted at indicating the prevalence, indication and outcomes of hysterectomy in the study area.

In this study from the total case, $94(47 \%)$ of cases had uterine rupture. This was greater than study conducted in Indian which accounted 4(21\%) of cases had uterine ruptures. The possible explanation of the difference could be there was low ANC coverage in our study[17]

In this study, out of 200 women operated for emergency hysterectomies $20(10 \%)$ had outcome of death. This was less than study conducted in Gelemso Hospital which was $32(21 \%)$.The possible explanation of the discrepancy might be in our study women come from short distance than Galemso hospital \& absence of delay in referral linkage system [18].

In this study para II -IV 52\% which was the highest incidence of uterine rupture. This was greater than study conducted in Addis Ababa which was 5.6\% Gravida II - IV Incidence of uterine rupture. The possible explanation of the difference could be the highest rate of previous of home delivery [19].

In this study Procedentia accounts 24(12\%) of all hysterectomy done. This less than study conducted Gelemso hospital which was 280(75\%).The possible explanation of this difference might be the small number of mothers gave birth by vaginal delivery compare to Gelemso hospital [18].

As our study revealed, the incidence of uterine rupture was 1 case per 10 deliveries who didn't follow antenatal care (40\%) and the pregnant women who had no antenatal care and later died of uterine rupture were $10 \%$. This was less than study conducted in Jimma Specialized Hospital which was the incidence of uterine rupture was 1 case per 37 deliveries which also shows the higher incidence compared to this study it shows that the uterine rupture was common in pregnant women who didn't follow antenatal care (92.6\%) and the pregnant women who had no antenatal care and later died of uterine rupture were $28.15 \%$. 
This could be explained by widely distributed medical care including obstetric care in different level and early referral to hospital for early diagnosis and prompt therapy which decreases the catastrophic complications [20].

\section{Conclusion}

This study despite its limitations showed the various indications for hysterectomies in study areas and the incidence of uterine rupture was higher rate in those who have no ANC follow up and in those who were multipara. The poor Transportation \&distance of locality from the Hospital have a great role in incidence of uterine rupture \& its outcomes.

In order to reduce case of uterine rupture, which is partially due to lack of antenatal care for identification of high risk groups, improved health information of the community at large is required and also more hospitals with maternity units and more health centers manned by well trained personnel will need to be established along with better home deliveries. This will entail the training of obstetricians, midwives \& traditional birth attendants. Transport and communication must be improved so that early \& prompt referral of patients to hospital in case of emergency is feasible.

By training lower level health workers who could provide many of the health services needed by the people one can increase health man- power, increase coverage and reach people at community level.

\section{Methods}

\subsection{The aim, design setting and area of the study}

Institutional based retrospective study was conducted in Goba Referral Hospital to assess the magnitude, indications and outcomes of hysterectomy in Goba Referral Hospital, Bale Zone; South East Ethiopia.

Goba Referral Hospital was founded in 1974. The Hospital gives both outpatient and inpatient health service. The hospital first gynecologist was employed in 2010. During our data collection period, there were two surgeons, 30 general practitioners and 100 nurses in the hospital as full time workers. The hospital has four major wards which have a total of 80 beds, from which 20 beds were assigned for obstetric cases. The hospital also has one operation theater room. The Hospital gives health service for 22 Woreda with the maximum distance of $200 \mathrm{~km}$. In general it gives health service for total population of $1,084,446$. This 
study encompasses those cases registered from January 1, 2008 to January 1, 2018 in Goba Referral Hospital.

Goba is a town and separate woreda in south-central Ethiopia. Located in the Bale Zone of the Oromia Region approximately $446 \mathrm{~km}$ southeast of Addis Ababa, this city has a latitude and longitude of $7^{\circ} 0$ N $39^{\circ} 59^{\prime} \mathrm{E}$ and an elevation of 2,743 meters above sea level. The 2007 national census reported a total population for Goba of 32,025, of whom 15,182 were men and 16,843 were women; 4,797 or $6.13 \%$ of its population were urban dwellers. The majority of the inhabitants said they practiced Ethiopian Orthodox Christianity, with $69.84 \%$ of the population reporting they observed this belief, while $23.12 \%$ of the population was Muslim and 5.84\% were Protestant[15][16]

\subsection{Data collection method and instrumentation and statistical analysis}

Data were retrieved from operation room records using self-administered structured checklists.After checking the data for completeness, missing values and coding of the checklist. The data were entered into Epi data version 3.1(Epi-Data, Odense, Denmark) and analyzed by using Statistical Package for Social Science (SPSS) version 20 (IBM, Chicago, IL, U.S.A). Continuous and categorical variables were summarized by tables, graph and descriptive statistics. Logistic regression was used to determine association between predictors and hysterectomy prevalence. P-value $<0.05$ was -considered as statistically significant.

\subsection{Data quality management}

The operation room records, the discharge book of the wards and the patient's card was counter checked to improve the quality of the data. Data consistency and completeness was checked throughout the data collection, entry and analysis.

\section{Operational definition}

Maternal death: the death of women while pregnant or within 42 days of termination of pregnancy from any cause related to or aggravated by pregnancy or its management but not from accidental or incidental cases.

Postpartum hysterectomy: is hysterectomy done for hemorrhage which is unresponsive to other treatment. 
Partial ANC: if the Mather did not complete 4 visits during pregnancy.

Full ANC: if she completes 4 visits during pregnancy.

Outcome of hysterectomy: any problem associated with health after hysterectomy.

\section{Lists of abbreviation}

JUSH Jimma University Specialized Hospital

$A N C$ Antenatal care

$C / S$ Caesarian section

$O L$ Obstructed Labor

TAH ..Total abdominal hysterectomy CPD Cephalopelvic disproportion 


\section{Declaration}

\section{Ethics approval and consent to participate}

Before data collection the proposal was submitted and after approval letter was obtained from Jimma University Institute of Health, Faculty of Health Science research review board. Verbal consent was obtained from medical director and head nurse of Goba referral Hospital The confidentiality the information we collect under the course of the study was kept. We, the authors of this manuscript declare that there is no conflict of interest.

\section{Consent for publication}

Verbal consent from medical director and head nurse of Goba Referral Hospital was obtained after we have clearly explain the aim of the study, about the procedure, the benefit, incentive if any and about the confidentiality and their right to refuse or stop the study any time they like.

\section{Availability of data and materials}

The datasets used and/or analyzed during this study are available from the corresponding author on reasonable request.

\section{Competing interests / Conflict of interests}

The author(s) have no competing interests for financial support, publication of thisresearch, patents and royalties through this collaborative research. All authors were equally involved in discussed research work. There is no financial conflict with the subject matter discussed in this manuscript.

\section{Funding for the research}

This research was funded Jimma University, Institute of Health, Faculty of health, School of medicine, undergraduate research coordinating office.

\section{Authors contributions}

Akililu G, Takele M, and Yaregal A, were involved in conception, design, and acquisition of data. Aklilu G, and Takele M, took the lead in data generation, analysis and drafting the manuscript. Aklilu G, and Yaregal A, revised the draft manuscript critically for important intellectual content. All authors were involved in analysis and interpretation of the data, as well as final approval of the version to be published. 


\section{Acknowledgments}

We would like to thank all the medical and administrative staffs of GobaReferral hospital for their kind support during the data collection time in providing all the necessary information for the data collection.

Author's information

The corresponding author Aklilu G, and Takele M, are from Jimma university, while Yaregal A, is from Bahir Dar University. 


\section{References}

[1] R. Lonnée-hoffmann and I. Pinas, "Effects of Hysterectomy on Sexual Function," no. I, pp. 244-251, 2014.

[2] C. Shekhar, B. Paswan, and A. Singh, "Prevalence, sociodemographic determinants and selfreported reasons for hysterectomy in India," Reprod. Health, vol. 16, no. 1, pp. 1-16, 2019.

[3] A. S. Review, T. Van Den Akker, and C. Brobbel, "Outcomes of Emergency Peripartum Hysterectomy Worldwide," vol. 128, no. 6, pp. 1281-1294, 2016.

[4] N. Reis, R. Engin, M. Ingec, and B. Bag, "A qualitative study : beliefs and attitudes of women undergoing abdominal hysterectomy in Turkey," no. 10, pp. 921-928, 2008.

[5] P. Bhugra, "Hysterectomy : retrospective analysis of 476 cases," vol. 9, no. 5, pp. 1930-1933, 2020.

[6] I. Briedite, G. Ancane, I. Rogovska, and N. Lietuviete, "Quality of Female Sexual Function after Conventional Abdominal Hysterectomy - Three Months ' Observation," vol. 2014, no. 7, pp. 26-31, 2014.

[7] Y. Wang and X. Ying, "Sexual function after total laparoscopic hysterectomy or transabdominal hysterectomy for benign uterine disorders : a retrospective cohort," vol. 53, pp. 1-7, 2020.

[8] Y. Berhan and A. Berhan, "Causes of maternal mortality in Ethiopia: a significant decline in abortion related death," Ethiop. J. Health Sci., vol. 24, no. 8, pp. 15-28, 2014.

[9] A. Simsek et al., "Female sexual function after transobturator tape in women with urodynamic stress urinary incontinence," J. Korean Phys. Soc., vol. 3, no. 1, pp. 1-5, 2014.

[10] O. Access, "The information requirements and self-perceptions of Turkish women undergoing hysterectomy," vol. 32, no. 1, pp. 165-170, 2016.

[11] No Title. 2014.

[12] No Title. 2013.

[13] J. Ekabua, K. Ekabua, and C. Njoku, "Proposed Framework for Making Focused Antenatal Care Services Accessible: A Review of the Nigerian Setting," ISRN Obstet. Gynecol., vol. 2011, pp. 1-5, 2011.

[14] "heyster-12.pdf." .

[15] Camerapix, Camerapix Spectrum Guide to Ethiopia, 2nd editio. Camerapix Publishers Internationa, 2000.

[16] C. Statistical, "2007 POPULATION and HOUSING CENSUS OF ADMINISTRATIVE," no. April, 2012.

[17] L. Mideksa and T. Alemayehu, "Outcome of Hysterectomy and Associated Risk Factors in Gelemso Zonal Hospital of Western Hararge, Ethiopia Outcome of Hysterectomy and Associated Risk Factors," no. January, 2015.

[18] M. M. Amanuel Gessessew, “Obstructed Labour in Adigrat Zonal Hospital Tigray Region, 
Ethiopia," Ethiop J Health Dev. p. 17, 2003.

[19] G. Astatikie, M. A. Limenih, and M. Kebede, "Maternal and fetal outcomes of uterine rupture and factors associated with maternal death secondary to uterine rupture," pp. 1-9, 2017.

[20] D. Negussie and N. Mesfin, "Original Article Review of Maternal Specialized Hospital in," Heal. (San Fr., pp. 9-12.

spring plus.

Ethiopian journal of health development 